\title{
Detection of Coronavirus Disease (COVID-19) using Radiological Examinations
}

\author{
Muhammad Shahzeb ${ }^{1}$ (D), Areena Khan $^{1}$ (D) and Anees Muhammad ${ }^{2 *}$ (iD) \\ ${ }^{1}$ Department of Radiology, College of Medical Technology (BKMC) Mardan, Pakistan. ${ }^{2}$ Department of Medical \\ Laboratory Technology, College of Medical Technology, Bacha Khan Medical College, Mardan, Pakistan.
}

\begin{abstract}
An outbreak of Coronavirus disease 2019 (COVID-19) occurred in China. The causative agent of COVID-19 is Severe Acute Respiratory Syndrome Coronavirus 2 (SARS-CoV-2). The disease rapidly spreads from China to the world by trading and traveling. Until April 24, 2020, approximately 2,544,792 cases were confirmed with 175,694 deaths throughout the world. The highest number of cases were identified from the United States of America (USA) whereas the mortality rate is high in Portugal. The diagnosis of COVID-19 is based on Computed Tomography Scanning (CT Scan) and Real-Time Reverse Transcription Polymerase Chain Reaction (qRT-PCR). Assessing the extension of pathology, the exact location of the area involved, and assessment of the disease severity makes CT scan superior to other modalities. This review shows that real-time polymerase chain reaction and imaging technology both play an important role in the diagnosis of COVID-19. However, imaging modalities have more importance in diagnosis and screening than qRT-PCR. The qRT-PCR was positive in $\mathbf{8 1 . 3 \%}$ whereas CT scan abnormality was observed in $\mathbf{8 9 . 8 \%}$. Bilateral lobe $\mathbf{( 5 1 . 4 \% )}$ abnormality was found more than a single lobe $\mathbf{2 1 . 5 \% )}$ in COVID-19 infected patients. The CT scan reports show a high-level abnormality in right lower lung lobe than others in COVID-19 infected patients. The CT scan evaluates different manifestations such as the presence of ground-glass opacities, consolidations, crazy paying linear, cavitation, discrete nodules, pleural effusion, and lymphadenopathy. It is concluded that imaging technology especially CT scan and $X$-rays play an important role in the screening and diagnosis of COVID-19 infected patients in limited access to qRT-PCR regions. The common radiological manifestation was also determined, which will be helpful for the radiologist to diagnosed COVID-19 infected patients in the early stages. Follow up studies required regarding the radiological examinations.
\end{abstract}

Keywords: Computed Tomography scanning, Consolidation, COVID-19, Ground glass opacity, Real-time polymerase chain reaction

*Correspondence: aneesafridi15295@yahoo.com; +92-344-9112106

(Received: April 02, 2020; accepted: April 25, 2020)

Citation: Shahzeb M, Khan A, Muhammad A. Detection of Coronavirus Disease (COVID-19) using Radiological Examinations. J Pure Appl Microbiol. 2020;14(suppl 1):911-920. doi: 10.22207/JPAM.14.SPL1.28

C The Author(s) 2020. Open Access. This article is distributed under the terms of the Creative Commons Attribution 4.0 International License which permits unrestricted use, sharing, distribution, and reproduction in any medium, provided you give appropriate credit to the original author(s) and the source, provide a link to the Creative Commons license, and indicate if changes were made. 


\section{INTRODUCTION}

The Coronavirus disease 2019 (COVID-19) is caused by Severe Acute Respiratory Syndrome Coronavirus 2 (SARS-2), which was reported from China. ${ }^{1}$ the COVID-19 shed from Wuhan to whole China and to the rest of the world. ${ }^{2}$ The newly discovered SARS-CoV-2 belongs to the family Coronaviridae and order Nidovarales. Severe Acute Respiratory Syndrome (SARS), and the Middle East Respiratory Syndrome (MERS) also belong to the same family. ${ }^{3}$ The SARS and MERS also belong to the same groups. For the first time, the SARS outbreak was reported in Southern China and was rapidly declared global threat in March 2003. ${ }^{4}$ About 8,000 cases were identified with 774 deaths throughout the world. Similarly, MERS was reported from Saudi Arabia in 2012, resulting in 2,494 cases with 858 deaths. ${ }^{5,6}$ Until April 24, 2020 , a total of $2,544,792$ confirmed cases with 175,694 deaths globally occurred with COVID-19. ${ }^{7}$ The mortality rate of MERS was highest among the SARS, MERS, and COVID as shown in Fig. 1.

Transmission, Clinical Manifestation, Diagnosis, and Treatment of COVID-19

It is reported that COVID-19 was spread in the local market of Wuhan City, with seafood and animal meat. ${ }^{8}$ The transmission from Wuhan city to the rest of China occurred by traveling of infected individuals. Then, it spread to the world by a similar mechanism of the infected population. ${ }^{9}$ The transmission of COVID-19 occurred by respiratory droplets and close contact with infected person. ${ }^{10}$ The COVID-19 infection causes respiratory distress from mild to severe. The common symptoms are fever, dry cough, fatigue and myalgia, shortness of breath, pneumonia, dizziness, and other comorbidities. ${ }^{11,12} \mathrm{~A}$ few rare symptoms are also noted in COVID-19 infected persons such as headache, rhinorrhea, and hemoptysis. ${ }^{13,14}$
The pulmonary disorders may lead to severe respiratory disorders and even death. The susceptible patients such as immunocompromised and older aged individuals are more prone to COVID-19. ${ }^{15}$ Not only the COVID-19 infected patients having the symptoms are a source of infection but the asymptomatic patients in the incubation period can also the source of infection. Therefore, early diagnosis is crucial for the identification of asymptomatic patients.

Laboratory-based procedures and radiological examinations are both can be used for screening and diagnosis of COVID-19. The Real-Time Reverse Transcription Polymerase Chain Reaction (qRT-PCR) is considered as a reference or standard diagnostic technique but false-negative results in asymptomatic patients and human error can decrease the role qRT-PCR in the diagnosis of COVID-19. ${ }^{16,17}$ However, imaging technology especially the computed tomography scanning (CT-Scan) and X-ray can play a crucial role in the diagnosis of COVID-19 patients in early stages. ${ }^{18-20}$ There is no specific vaccine and drugs are available for COVID-19.

\section{Current Status of COVID-19}

According to the World Health Organization (WHO), the number of COVID-19 cases and deaths are increasing day by day throughout the world. Currently, the regions of America and Europe are the epicenter of SARSCoV-2 after Wuhan, China. Till to April 24, 2020, a total of 2,544,792 reported cases with 175,694 deaths are globally identified. The highest number of cases are determined in European regions (1,251,458 cases and 113,336 deaths), followed by regions of America $(957,402$ cases and 47812 deaths), Eastern Mediterranean regions (144,450 cases and 6469 deaths), Western Pacific regions (137,902 cases and 5818 deaths), South East

\section{Mortality rate}

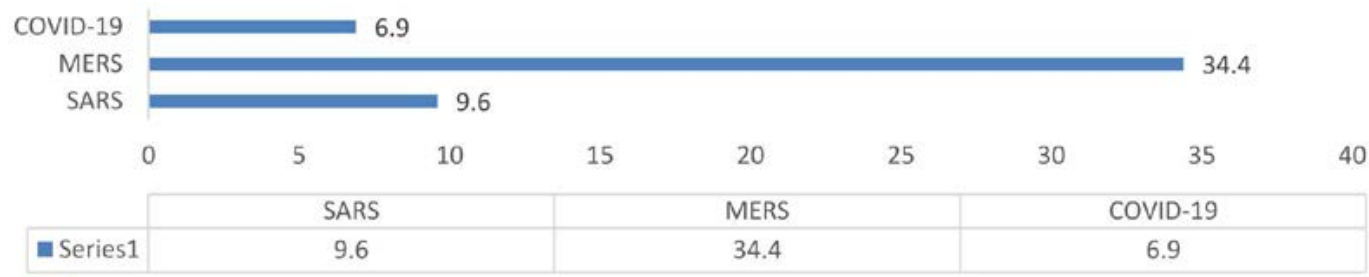

Fig. 1. Mortality rate of SARS, MERS and COVID-19 (as April 24, 2020) 
Asia regions (36,039 cases and 1498 deaths) and African Regions (16,829 cases and 748 deaths) as shown in Fig. 2. ${ }^{7}$

The cases in United State (US) was 800,926 having 5.0 mortality rate, followed by
Spain 20,8389 cases with $10.4 \%$ mortality, Italy 187,327 cases with $13.4 \%$ mortality, Germany 148,046 cases with $3.4 \%$ mortality, the United Kingdom 133,499 cases with $13.5 \%$ mortality rate, France 117,961 cases with $18.1 \%$ mortality, Turkey

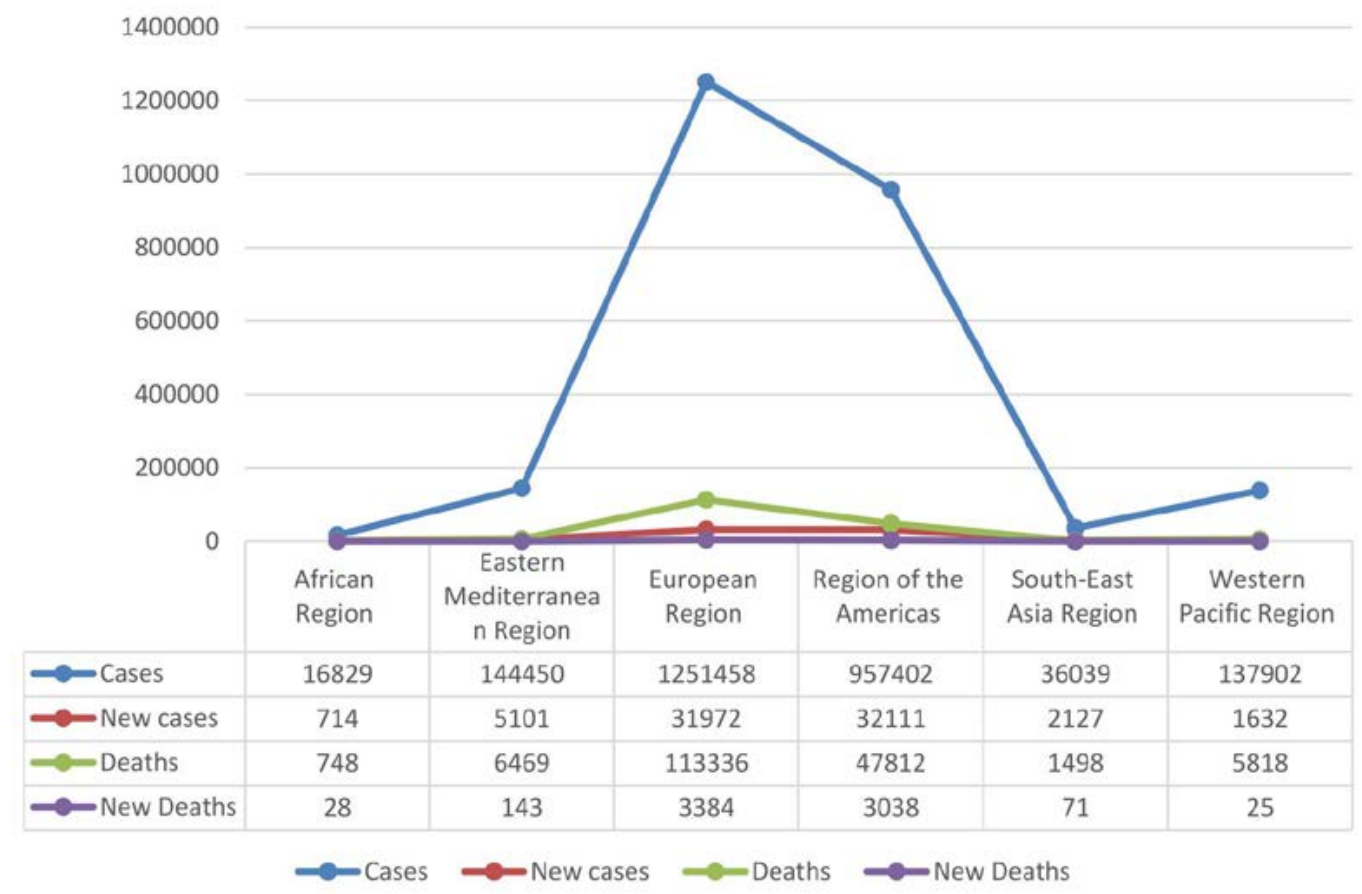

Fig. 2. Continental based cases of COVID-19

98674 cases with $2.4 \%$ mortality, Iran 85,996 cases with $6.2 \%$ mortality and China 82,631 cases wit $4.0 \%$ mortality as shown in Fig. $3 \& 4 .^{7}$

Clinical manifestation and role of radiology in Detection of COVID-19

Radiological examinations play a major role in the prompt identification of COVID-19. The typical finding of COVID-19 is multifocal groundglass opacities, distributed peripherally, along with the patchy consolidations that are quite challenging to be picked on chest radiographs showing it as a normal chest $\mathrm{X}$-ray initially. ${ }^{21} \mathrm{After}$ a week or more, the Chest radiography of COVID-19 infected patients shows various abnormalities including air bronchogram, diffuse air space and patchy opacities, like other Coronavirus pneumonia. ${ }^{22,23}$ Due to its low contrast resolution, chest radiography was not considered as a standard imaging modality for finding Coronavirus Disease 2019 (COVID-19). Whereas, thin-slice CT scan Chest is preferred over chest $\mathrm{X}$-ray because of its fast speed, accuracy, high sensitivity, improved contrast resolution, and early detection of COVID-19 pneumonia. ${ }^{17}$ The main COVID-19 pneumonia findings picked by CT scan Chest are multifocal bilateral ground-glass opacities with patchy consolidations, marked peripherally subpleural distribution and preferred posterior part or inferior lobe involvement reversed halo sign which is an area of rounded ground glass bounded completely or incompletely by a consolidation ring. ${ }^{3,20,21}$ While the rare findings on CT scan chest are pleural effusion, pulmonary cavitation, calcification, and lymph node enlargement. 3 ,23-25 The CT scan of few severe patients shows diffuse mixed consolidations having ground-glass opacities present in bilateral lungs with air bronchial sign and bronchiectasis, giving the appearance of "white lung". ${ }^{8}$ Thickening of interlobar septa and bilateral pleura with minimal pleural effusion is also 


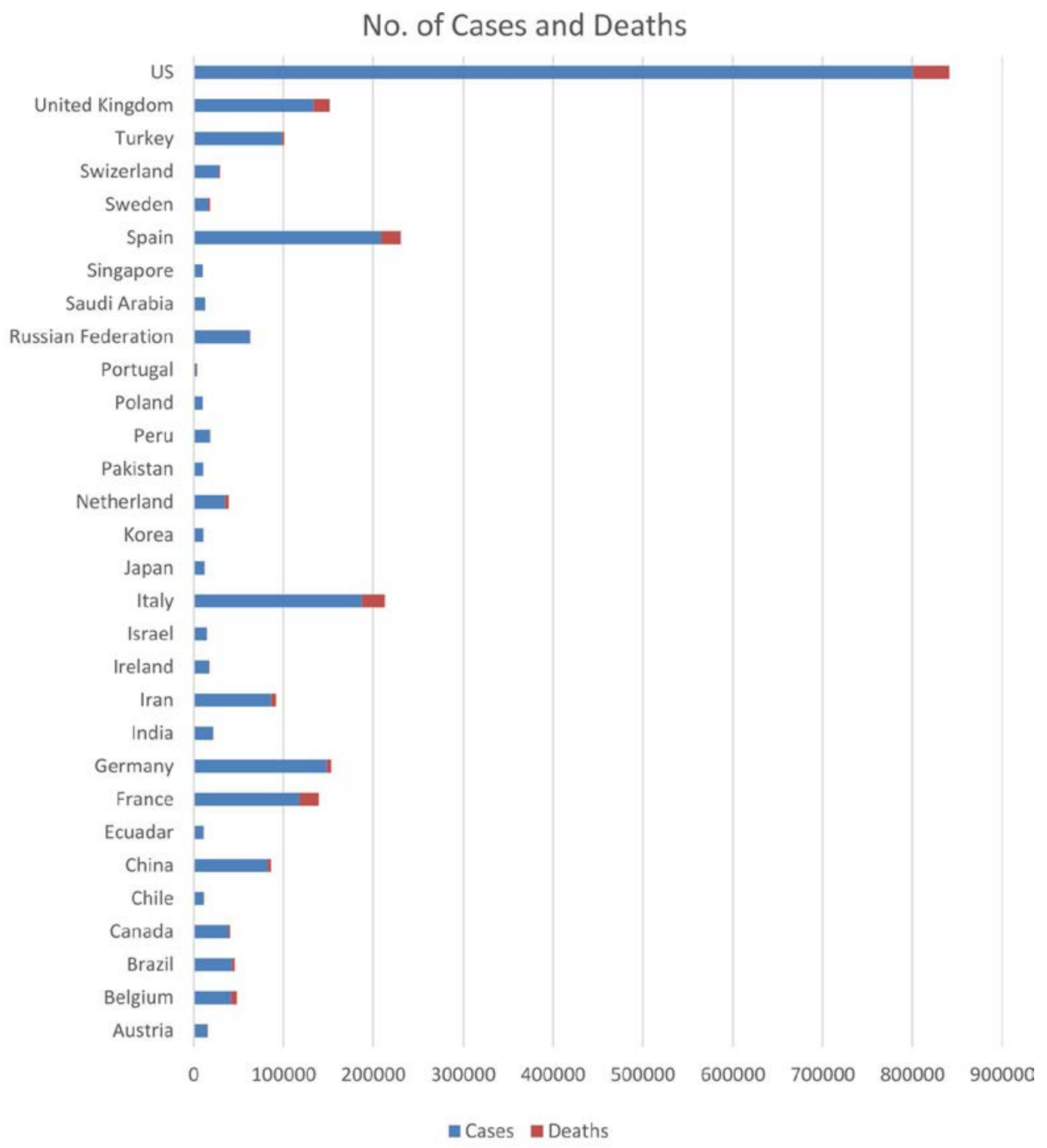

Fig. 3. Number of Cases and Deaths with COVID-19 in several countries

observed in few patients. ${ }^{16,26} \mathrm{~A}$ semi-quantitative scoring system ranged from 0 to 5 may be used for pulmonary abnormalities caused by COVID-19. ${ }^{27}$ Based on the previous findings, the right lower lobe is more affected by COVID-19, followed by the left lower lobe, left upper lobe, right upper lobe and middle lobe of left lung. ${ }^{28}$ Few patients had normal CT chest reports on initial examination, quite a few patients had a unilateral lung infection, and about $78 \%$ of patients suffered from a bilateral lung infection. Ground-glass opacity (GGO) is frequently observed in COVID-19 infected patients followed by consolidation, vascular enlargement, inter-lobar septal thickening, and mixed GGO. ${ }^{29}$

Present Review Findings

A total of 6 studies were retrieved in which qRT-PCR and CT scan examination were compared. In total 6 studies, 1275 individuals were studied in which male patients were 599, and female patients were 676. Among the studied individuals, $81.3 \%$ were confirmed positive by qRT-PCR whereas, CT scan examination was found abnormal in $89.8 \%$ patients ass shown in Table 1. 


\section{Mortality rate of COVID-19 in various Countries}

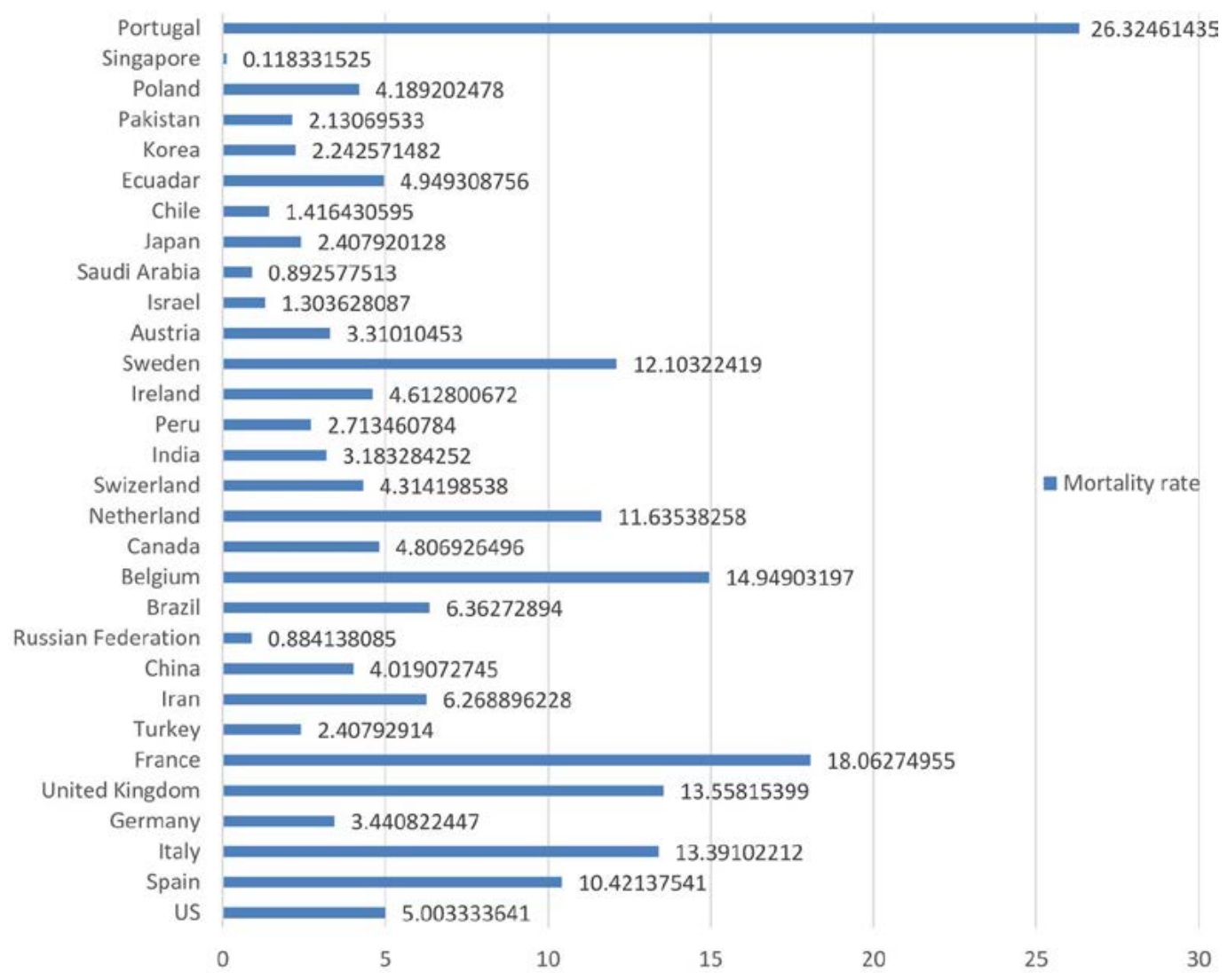

Fig. 4. The mortaliy rate of COVID-19 in various Countries

It was observed that bilateral lobes (51.4\%) of lungs were more affected than single lobe $(21.5 \%)$ of the lung. Both right and left lung was affected in COVID-19 with a percentage of $67.7 \%$ and $66.9 \%$ respectively. Among the four regions of lungs; right lower lung lobes were more affected than right upper lung lobes. Similarly, the left lower lung lobe was more affected than the left upper lung lobe as shown in Table 2.
CT scan manifestation of Coronavirus Disease (COVID-19)

Ground Glass Opacity was commonly reported in COVID-19 infected patients mostly noted in bilateral lungs. Consolidation is the second most common CT scan manifestation in the COVID-19 patients. Consolidations may be present in the patchy form, either distributed segmentally or in sub-pleural areas. The reticular pattern is

Table 1. Comparison of RT-PCR and CT scan reports in patients infected with COVID-19

\begin{tabular}{lllllllll}
\hline Authors & $\begin{array}{l}\text { Study } \\
\text { Country }\end{array}$ & No. of & $\begin{array}{l}\text { Male } \\
\text { Patients }\end{array}$ & $\begin{array}{l}\text { Female } \\
\text { Chean } \\
\text { Age }\end{array}$ & $\begin{array}{l}\text { RT-PCR } \\
\text { Positive }\end{array}$ & $\begin{array}{l}\text { CT } \\
\text { Abnormality }\end{array}$ & References \\
\hline Pan et al. & China & 21 & 06 & 15 & $40 \pm 9$ & $100 \%$ & $80.5 \%$ & 23 \\
Li et al. & China & 51 & 28 & 23 & $55 \pm 33$ & $100 \%$ & $96.1 \%$ & 29 \\
Fang et al. & China & 51 & 29 & 22 & $45 \pm 10$ & $71 \%$ & $98 \%$ & 30 \\
Bernheim et al. & New York & 121 & 61 & 60 & $45 \pm 3$ & $88 \%$ & $76 \%$ & 31 \\
Ai et al. & China & 1014 & 467 & 547 & $51 \pm 15$ & $59 \%$ & $88 \%$ & 32 \\
Zhang et al. & China & 17 & 8 & 9 & $48 \pm 6$ & $70 \%$ & $100 \%$ & 33 \\
\hline
\end{tabular}


Table 2. Lungs Morphology reported through CT scan in patients infected with COVID-19

\begin{tabular}{llllllll}
\hline Authors & \multicolumn{2}{l}{$\begin{array}{l}\text { Single lung } \\
\text { lobe }\end{array}$} & $\begin{array}{l}\text { Two or } \\
\text { more lobes }\end{array}$ & $\begin{array}{l}\text { Right upper } \\
\text { Lung Lobes }\end{array}$ & $\begin{array}{l}\text { Right lower } \\
\text { lung lobe }\end{array}$ & $\begin{array}{l}\text { Left upper } \\
\text { lung lobe }\end{array}$ & $\begin{array}{l}\text { Left lower } \\
\text { lung lobe }\end{array}$ \\
\hline Yen et al. & NA & NA & $67 \%$ & $76 \%$ & $76 \%$ & $81 \%$ & 21 \\
Pan et al. & $42 \%$ & $42 \%$ & NA & NA & NA & NA & 23 \\
Burnheim et al. & $15 \%$ & $12 \%$ & $44 \%$ & $65 \%$ & $48 \%$ & $63 \%$ & 31 \\
Wang et al. & $9.1 \%$ & $5.5 \%$ & NA & $3.6 \%$ & NA & $3.6 \%$ & 34 \\
Miao et al. & $41.6 \%$ & $44.6 \%$ & $41.9 \%$ & $71.0 \%$ & $48.4 \%$ & $66.1 \%$ & 35 \\
Miao et al. & $16.7 \%$ & $83.4 \%$ & $48.1 \%$ & $79.6 \%$ & $51.9 \%$ & $74.1 \%$ & 36 \\
Fu et al. & $66.7 \%$ & $72.2 \%$ & $72.2 \%$ & $100 \%$ & $66.7 \%$ & $88.8 \%$ & 37 \\
Chung et al. & $5 \%$ & $71 \%$ & $67 \%$ & $76 \%$ & $67 \%$ & $67 \%$ & 38 \\
Song et al. & $8 \%$ & $39 \%$ & $84 \%$ & $90 \%$ & $84 \%$ & $90 \%$ & 39 \\
Xu et al. & $13 \%$ & $59 \%$ & $53 \%$ & $66 \%$ & $53 \%$ & $61 \%$ & 40 \\
Lomoro et al. & $2.4 \%$ & $85.7 \%$ & $92.9 \%$ & $92.9 \%$ & $92.9 \%$ & $90.5 \%$ & 41 \\
\hline
\end{tabular}

mostly observed in patients of age more than 50 years or when the disease gets longer. Crazy paving pattern and cavitation was also reported in COVID-19 infected patients. Discrete nodules was another CT scan manifestation in COVID-19 infected patients. Halo sign, lymphadenopathy, and vascular enlargement was also reported in
COVID-19 infected patients as shown in Table 3 \& 4.

\section{Differential Diagnosis of Coronavirus Disease} (COVID-19)

Initially, every type of infection appears normal on Chest X-ray but with time, the signs become apparent as soon as infection causes

Table 3. Common reported CT scan findings in patients infected with COVID-19

\begin{tabular}{lcccccccccc}
\hline Authors & I & II & III & IV & V & VI & VII & VIII & IX & X \\
\hline Yen et al. & $86 \%$ & $62 \%$ & NA & NA & $1 \%$ & NA & NA & NA & $86 \%$ & 21 \\
Pan et al. & $75 \%$ & $41 \%$ & $25 \%$ & NA & NA & NA & NA & $42 \%$ & $54 \%$ & 23 \\
Bernheim et al. & $34 \%$ & $34 \%$ & $20 \%$ & $1 \%$ & NA & $1 \%$ & $1 \%$ & $60 \%$ & $40 \%$ & 31 \\
Wang et al. & $27.3 \%$ & $27.3 \%$ & NA & NA & NA & $0.9 \%$ & NA & $56.4 \%$ & $43.6 \%$ & 34 \\
Miao et al. & $62.9 \%$ & $19.4 \%$ & $27.4 \%$ & $1.6 \%$ & NA & NA & NA & $67.7 \%$ & $54.8 \%$ & 35 \\
Miao et al. & $70.4 \%$ & $22.2 \%$ & $29.6 \%$ & $1.3 \%$ & $19.7 \%$ & $5.3 \%$ & NA & $40.8 \%$ & $27.6 \%$ & 36 \\
Chung et al. & $57 \%$ & $29 \%$ & $19 \%$ & NA & NA & NA & NA & $76 \%$ & $33 \%$ & 38 \\
Song et al. & $77 \%$ & $55 \%$ & NA & NA & $22 \%$ & $8 \%$ & $6 \%$ & $84 \%$ & $86 \%$ & 39 \\
Xu et al. & $72 \%$ & $13 \%$ & $12 \%$ & NA & NA & $4 \%$ & $1 \%$ & $59 \%$ & $51 \%$ & 40 \\
Lomoro et al. & $95.2 \%$ & $25.9 \%$ & $57.1 \%$ & NA & NA & $7.1 \%$ & $14.3 \%$ & $64.3 \%$ & $28.6 \%$ & 41 \\
Wang et al. & $45 \%$ & $23 \%$ & $3 \%$ & NA & NA & NA & NA & $85 \%$ & $75 \%$ & 42 \\
Lu et al. & $76.9 \%$ & $64.2 \%$ & $61.5 \%$ & NA & $16.5 \%$ & NA & NA & $82.4 \%$ & $60.9 \%$ & 43 \\
Li et al. & $97.6 \%$ & $63.9 \%$ & $36.1 \%$ & NA & NA & NA & NA & $90 \%$ & $85 \%$ & 44 \\
Liu et al. & $76 \%$ & $24 \%$ & NA & NA & NA & NA & NA & $65 \%$ & NA & 45 \\
Xia et all. & $60 \%$ & $50 \%$ & NA & NA & $15 \%$ & NA & NA & $50 \%$ & $30 \%$ & 46 \\
Han et al. & $86 \%$ & $41 \%$ & $40 \%$ & NA & NA & NA & NA & $65 \%$ & $97 \%$ & 47 \\
Wu et al. & $91 \%$ & $63 \%$ & $29 \%$ & NA & NA & $6 \%$ & $4 \%$ & $95 \%$ & $53 \%$ & 48 \\
Wu et al. & $87.0 \%$ & $21.7 \%$ & NA & NA & $13.9 \%$ & NA & NA & $80.4 \%$ & $69.6 \%$ & 49 \\
Yoon et al. & $35 \%$ & $5 \% \%$ & $10 \%$ & NA & NA & NA & NA & $97 \%$ & $75 \%$ & 50 \\
\hline
\end{tabular}

I- Ground-glass opacity; II- Consolidation; III-Crazy-paving, Linear; IV-Cavitation; V-Discrete nodules;

VI-Pleural effusion; VII-Lymphadenopathy; VIII-Bilateral distribution; IX-Peripheral distribution; X-References 
parenchymal changes such as consolidations, pleural effusion, edema, or other different types of opacities. A thin slice CT scan is the standard modality to rule out the exact nature and location of pathology. The thin slice CT scan shows the changes in the form of different opacities based on the degree of X-ray attenuation. The CT scan manifestations of viral and bacterial infection are the same as COVID-19 infected patients such as ground-glass opacity, consolidations, crazy paving patterns, nodules, halo sign, reticular pattern, or vessel enlargement but the changes occur through the proper pattern in COVID-19 infected patients. After the onset of symptoms, the common imaging features are the pure and mixed groundglass opacities. At 0-5 days, mostly the pure ground-glass opacities are present while on illness days $0-12$, the pure ground-glass opacities

Table 4. Case reports and Case presentations reported from around the world

\begin{tabular}{|c|c|c|c|c|c|c|c|}
\hline Author & Country & Age & Gender & RT-PCR & Lungs Affected & CT Presentation & References \\
\hline Liu et al. & China & 41 & female & Positive & $\begin{array}{l}\text { Bilateral } \\
\text { lung lobes }\end{array}$ & $\begin{array}{l}\text { Ground glass opacity } \\
\text { without consolidation }\end{array}$ & 22 \\
\hline Lei et al. & China & 33 & Female & Positive & $\begin{array}{l}\text { Bilateral } \\
\text { lung lobes }\end{array}$ & Ground glass opacity & 22 \\
\hline Zou et al. & China & 55 & Male & Positive & $\begin{array}{l}\text { Right upper } \\
\text { and left upper }\end{array}$ & $\begin{array}{l}\text { Ground glass opacity } \\
\text { with consolidation }\end{array}$ & 51 \\
\hline Li et al. & China & 27 & Female & Positive & Right upper lobe & $\begin{array}{l}\text { Nodule with } \\
\text { ground-glass halo }\end{array}$ & 52 \\
\hline Kong et al. & China & 59 & Female & Positive & Right Lower Lobe & Ground glass opacity & 53 \\
\hline Kong et al. & China & 62 & Female & Positive & Left Upper Lobe & $\begin{array}{l}\text { Small Solitary nodular } \\
\text { Ground glass opacity } \\
\text { Consolidation and crazy } \\
\text { paying pattern }\end{array}$ & 53 \\
\hline Kong et al. & China & 45 & Female & Positive & $\begin{array}{l}\text { Right and Left } \\
\text { upper lobe }\end{array}$ & $\begin{array}{l}\text { Peripheral Ground glass } \\
\text { opacity in bilateral } \\
\text { upper lobe }\end{array}$ & 53 \\
\hline Liew et al. & China & 53 & Male & Positive & $\begin{array}{l}\text { Left and right } \\
\text { lower lobe }\end{array}$ & $\begin{array}{l}\text { Presence of consolidation } \\
\text { and ground glass opacity }\end{array}$ & 54 \\
\hline Shi et al. & China & 42 & Male & Positive & $\begin{array}{l}\text { Left lower and } \\
\text { right upper lobe }\end{array}$ & $\begin{array}{l}\text { Bilateral ground } \\
\text { glass opacity }\end{array}$ & 55 \\
\hline
\end{tabular}

are followed by the mixed ones. Consolidation is the second common imaging feature that occurs along with ground glass opacities on illness days 6-11. The uncommonly seen reticular pattern was only obvious on illness days 18-23 or onwards. Other changes, such as nodules, edema, lymphadenopathy, and pleural effusion also occur in COVID-19 infected patients but they may also be associated with other diseases such as chronic obstructive pulmonary disease (COPD), hypertension, etc.

\section{CONCLUSION}

In conclusion, both laboratory and radiological examinations can diagnose COVID-19 in infected patients. Though qRT-PCR is considered as a standard reference to rule out the COVID-19 the false-negative results provided by qRT-PCR compromise its accuracy. While in radiological examinations, although X-ray plays an important role as an initial examination to detect the coronavirus disease, CT scan chest is preferred over X-ray modality because of its accuracy, improved contrast resolution, high sensitivity and ability to pick the disease in the initial phase, unlike $X$-ray which shows indefinite findings of most of the lung lesions.

The typical features of coronavirus detected on CT scan chest are bilateral groundglass opacities, consolidations, reticular pattern, crazy paving pattern, halo sign, and nodules. Yet, most studies were done on epidemiology and 
the causes of COVID-19. While, this review article focuses on the role of radiology in detecting the disease along with the epidemiology, control, and prevention. Relying on the baseline CT scan features and not considering the follow-up scans of infected patients is the limitation of this study. Moreover, the article reviewed only those studies done during the early outbreak of the disease. However, the study depicts the importance of radiology in the diagnosis, prevention, and control of the COVID-19.

\section{ACKNOWLEDGMENTS}

None.

\section{CONFLICT OF INTEREST}

The listed author(s) declare no conflict of interest in any capacity, including competing or financial.

\section{AUTHORS' CONTRIBUTION}

All listed author(s) have made a substantial, direct and intellectual contribution to the work, and approved it for publication.

\section{FUNDING}

None.

\section{ETHICS STATEMENT}

This article does not contain any studies with human participants or animals performed by any of the authors.

\section{AVAILABILITY OF DATA \\ Not applicable.}

\section{REFERENCES}

1. Wang W, Tang J, Wei F. Updated understanding of the outbreak of 2019 novel coronavirus (2019-nCoV) in Wuhan, China. J Med Vir. 2020;92(4):441-7.

2. Yuan Y, Qi J, Peng R, et al. Molecular basis of binding between Middle East Respiratory Syndrome Coronavirus and CD26 from seven bat species. J Med Vir. 2020;14;94(5).

3. Kim H. Outbreak of novel coronavirus (COVID-19): What is the role of radiologists?. Euro Radio. 13 February 2020. https://doi.org/10.1007/s00330-02006748-2

4. Guan $\mathrm{Y}$, Zheng BJ, He YQ, et al. Isolation and characterization of viruses related to the SARS coronavirus from animals in southern China. Science. 2003;10;302(5643):276-8.

5. Oboho IK, Tomczyk SM, Al-Asmari AM, et al. 2014
MERS-CoV outbreak in Jeddah-a link to health care facilities. N Eng/ J Med. 2015;372(9):846-54.

6. Widjaja I, Wang C, van Haperen R, et al. Towards a solution to MERS: protective human monoclonal antibodies targeting different domains and functions of the MERS-coronavirus spike glycoprotein. Emer Micro \& Inf. 2019;8(1):516-30.

7. Organization WH. $<20200305$-sitrep-94-covid-19.pdf $>$. Coronavirus disease 2019 (COVID-19). 2020; Situation Report - 94(April 24, 2020).

8. Pan Y, Guan H, Zhou S, Wang Y, Li Q, Zhu T, et al. Initial CT findings and temporal changes in patients with the novel coronavirus pneumonia (2019-nCoV): a study of 63 patients in Wuhan, China. Eur Radiol. 2020;(December 2019).

9. Guan W-J, Ni Z-Y, Hu Y, et al. Clinical Characteristics of Coronavirus Disease 2019 in China. N Engl J Med [Internet]. 2020;1-13. Available from: http://www. ncbi.nlm.nih.gov/pubmed/32109013

10. Diao K, Han P, Pang T, Li Y, Yang Z. HRCT Imaging Features in Representative Imported Cases of 2019 Novel Coronavirus Pneumonia. Precis Clin Med. 2020;00(February):1-5.

11. Holshue ML, DeBolt C, Lindquist S, et al. First Case of 2019 Novel Coronavirus in the United States. N Engl J Med. 2020;929-36.

12. Li Q, Guan X, Wu P, et al. Early Transmission Dynamics in Wuhan, China, of Novel Coronavirus-Infected Pneumonia. N Engl J Med. 2020;1-9.

13. CDC. 2019 Novel coronavirus, Wuhan, China. 2020. https://www.cdc.gov/ coronavirus/2019-nCoV/ summary.html. Accessed 1 Feb 2020.

14. Huang $C$, Wang Y, Li X, et al. Clinical features of patients infected with 2019 novel coronavirus in Wuhan, China. Lancet. 2020;395:497-506.

15. Li T, Wei C, Li W, Hongwei F, Shi J. Beijing Union Medical College Hospital on "pneumonia of novel coronavirus infection" diagnosis and treatment proposal (V2.0). Med J Peking Union Med Coll Hosp. 2020. [ Accessed 2 Feb 2020]

16. Chinese Society of Radiology. Radiological diagnosis of new coronavirus infected pneumonitis: Expert recommendation from the Chinese Society of Radiology (First edition). Chin J Radiol, 2020,54(00): E001-E001.

17. Chan JF, Yuan S, Kok KH, et al. A familial cluster of pneumonia associated with the 2019 novel coronavirus indicating person-to-person transmission: a study of a family cluster. Lancet. 2020. S0140-6736(20)30154-9.

18. Fu H, Xu H, Zhang N, Xu H, Li Z. Association between Clinical , Laboratory and CT Characteristics and RT-PCR Results in the Follow-up of 2019 NOVEL CORONAVIRUS (2019-NCOV) patients. 2020;

19. General Office of National Health Committee. Office of state administration of traditional Chinese medicine. Notice on the issuance of a programme for the diagnosis and treatment of novel coronavirus (2019-nCoV) infected pneumonia (trial fifth edition) (2020-02-26).

20. Kanne JP. Chest CT findings in 2019 novel coronavirus (2019-nCoV) infections from Wuhan, China: key points for the radiologist. Radiology. 2020:200241. doi: 
10.1148/radiol.2020200241.

21. Ng M, Lee EYP, Yang J, et al. Imaging profile of the COVID-19 infection: Radiologic findings and literature review. Radiology: Cardiothoracic Imaging. 2020;2(1):e200034.

22. Liu P, Tan X. 2019 Novel Coronavirus (2019-nCoV) Pneumonia. Radiology. 2020;(8):200257.

23. Pan F, Ye T, Sun $P$, et al. Time Course of Lung Changes On Chest CT During Recovery From 2019 Novel Coronavirus COVID-19 Pneumonia. Radiology. 2020;200370.

24. Chung M, Bernheim A, Mei X, et al. CT imaging features of 2019 novel coronavirus (2019- nCoV). Radiology. 2020;200230.

25. Song F, Shi N, Shan F, et al. Emerging coronavirus 2019nCoV pneumonia. Radiology 2020:200274.

26. Lee KS. Pneumonia associated with 2019 novel coronavirus: can computed tomographic findings help predict the prognosis of the disease? Korean J Radiol 2020;21.

27. Zu ZY, Jiang M Di, Xu PP, et al. Coronavirus Disease 2019 2019 Novel Coronavirus (2019-nCov): A Perspective from China. Radiology [Internet]. 2020;2019:200490. Available from: http://www.ncbi.nlm.nih.gov/ pubmed/32083985

28. Ai T, Yang Z, Hou H, et al. Correlation of Chest CT and RT-PCR Testing in Coronavirus Disease 20192019 Novel Coronavirus (2019-nCov) in China: A Report of 1014 Cases. Radiology [Internet]. 2020;2019:200642. Available from: http://www.ncbi.nlm.nih.gov/ pubmed/32101510

29. Li Y, Xia L. Coronavirus Disease 20192019 Novel Coronavirus (2019-nCov): Role of Chest CT in Diagnosis and Management. AJR Am J Roentgenol [Internet]. 2020;(October):1-7. Available from: http://www.ncbi. nlm.nih.gov/pubmed/32130038

30. Fang $\mathrm{Y}$, Zhang $\mathrm{H}$, Xie J, et al. Sensitivity of chest CT for COVID-19: comparison to RT-PCR. Radiology. 2020;200432.

31. Bernheim $A$, Mei $X$, Huang $M$, et al. Chest $C T$ findings in coronavirus disease-19 (COVID-19): relationship to duration of infection. Radiology. 2020;200463.

32. Ai T, Yang Z, Hou H, et al. Correlation of chest CT and RTPCR testing in coronavirus disease 2019 (COVID-19) in China: a report of 1014 cases. Radiology. 2020;200642.

33. Zhang S, Li H, Huang S, You W, Sun H. High-resolution CT features of 17 cases of Corona Virus Disease 2019 in Sichuan province, China. European Respiratory Journal. 2020.

34. Wang K, Kang S, Tian R, Zhang X, Wang Y. Imaging manifestations and diagnostic value of chest CT of coronavirus disease 2019 (COVID-19) in the Xiaogan area. Clinical radiology. 2020.

35. Miao C, Zhuang J, Jin M, et al. A comparative multicentre study on the clinical and imaging features of comfirmed and uncomfirmed patients with COVID-19. medRxiv. 2020.

36. Miao C, Jin M, Miao L, et al. Early chest computed tomography to diagnose COVID-19 from suspected patients: A multicenter retrospective study. The American Journal of Emergency Medicine. 2020.

37. $\mathrm{Fu} \mathrm{H}, \mathrm{XuH}$, Zhang N, et al. Association between Clinical,
Laboratory and CT Characteristics and RT-PCR Results in the Follow-up of COVID-19 patients. medRxiv. 2020.

38. Chung M, Bernheim A, Mei X, et al. CT imaging features of 2019 novel coronavirus (2019-nCoV). Radiology. 2020;295(1):202-7.

39. Song F, Shi N, Shan F, et al. Emerging 2019 novel coronavirus (2019-nCoV) pneumonia. Radiology. 2020;295(1):210-7.

40. $\mathrm{Xu} \mathrm{X,} \mathrm{Yu} \mathrm{C,} \mathrm{Qu} \mathrm{J,} \mathrm{et} \mathrm{al.} \mathrm{Imaging} \mathrm{and} \mathrm{clinical} \mathrm{features}$ of patients with 2019 novel coronavirus SARS-CoV-2. European journal of Nuclear Medicine and Molecular Imaging. 2020;28:1-6.

41. Lomoro P, Verde F, Zerboni F, et al. COVID-19 pneumonia manifestations at the admission on chest ultrasound, radiographs, and CT: single-center study and comprehensive radiologic literature review. European Journal of Radiology Open. 2020;4:100231.

42. Wang $\mathrm{Y}$, Dong $\mathrm{C}$, Hu Y, et al. Temporal changes of CT findings in 90 patients with COVID-19 pneumonia: a longitudinal study. Radiology. 2020;200843.

43. Lu C, Yang W, Hu Y, et al. Coronavirus Disease 2019 (COVID-19) Pneumonia: Early Stage Chest CT Imaging Features and Clinical Relevance. https://dx.doi. org/10.2139/ssrn.3543606

44. Li K, Wu J, Wu F, et al. The Clinical and Chest CT Features Associated with Severe and Critical COVID-19 Pneumonia. Investigative Radiology. 2020 Feb.

45. Liu KC, Xu P, Lv WF, et al. CT manifestations of coronavirus disease-2019: a retrospective analysis of 73 cases by disease severity. European Journal of Radiology. 2020;108941.

46. Xia W, Shao J, Guo Y, Peng X, Li Z, Hu D. Clinical and CT features in pediatric patients with COVID-19 infection: Different points from adults. Pediatric Pulmonology. 2020.

47. Han R, Huang L, Jiang H, Dong J, Peng H, Zhang D. Early clinical and CT manifestations of coronavirus disease 2019 (COVID-19) pneumonia. American Journal of Roentgenology. 2020;1-6.f

48. Wu J, Wu X, Zeng W, Guo D, et al. Chest CT findings in patients with coronavirus disease 2019 and its relationship with clinical features. Investigative Radiology. 2020;55(5):257-61.

49. Wu X, Sun R, Chen J, Xie Y, Zhang S, Wang X. Radiological findings and clinical characteristics of pregnant women with COVID-19 pneumonia. International Journal of Gynecology \& Obstetrics. 2020.

50. Yoon $\mathrm{SH}$, Lee $\mathrm{KH}$, Kim JY, et al. Chest radiographic and CT findings of the 2019 novel coronavirus disease (COVID-19): analysis of nine patients treated in Korea. Korean Journal of Radiology. 2020;21(4):494-500.

51. Zou S, Zhu X. FDG PET/CT of COVID-19. Radiology. 2020;200770.

52. Li X, Zeng X, Liu B, Yu Y. COVID-19 infection presenting with CT Halo Sign. Radiology: Cardiothoracic Imaging . 2020;2(1):e200026.

53. Kong W, Agarwal PP. Chest imaging appearance of COVID-19 infection. Radiology: Cardiothoracic Imaging. 2020;2(1):e200028.

54. Liew JR, Lim YR, Liew JY, Poh CC. Clinics in Diagnostic Imaging: COVID-19 atypical pneumonia. Singapore Medical Journal. 2020. 
Shahzeb et al. | J Pure Appl Microbiol | 14(Spl Edn):911-920 | May 2020 | https://doi.org/10.22207/JPAM.14.SPL1.28

55. Shi H, Han X, Zheng C. Evolution of CT manifestations in a patient recovered from 2019 novel coronavirus (2019-nCoV) pneumonia in Wuhan, China. Radiology. 2020;295(1):20. 